\title{
Efficiency Analysis of Higher Education Institutions: Use of Categorical Variables
}

\author{
Prabhat Ranjan \\ Operations Management and Quantitative Techniques Area, \\ Indian Institute of Management Bodh Gaya, Bodh Gaya, Bihar, India. \\ E-mail: prabhat@iimbg.ac.in \\ Sanjeet Singh \\ Decision Sciences Area, \\ Indian Institute of Management Lucknow, Lucknow, Uttar Pardesh, India. \\ Corresponding author: sanjeet@iiml.ac.in
}

(Received on June 2, 2021; Accepted on September 19, 2021)

\begin{abstract}
This paper focuses on the Data Envelopment Analysis (DEA) based efficiency evaluation to find the impact of two-step categorical impact on the enrollment efficiency of colleges in Bihar, one of the largest states of India. The objective of the study is to find the impact of factors, other than college-specific, on the efficiency of the colleges. The proposed research includes colleges funded and managed through seven state public universities. To follow the homogeneity condition of DEA, colleges providing courses of Arts (languages and humanities only), Science, and Commerce only, have been selected. The numbers of students enrolled in undergraduate and postgraduate courses are considered as two outputs. Numbers of teaching and non-teaching staff are considered as inputs. Colleges have been classified into two categories based on their presence in the rural or urban areas. The efficiency of a college due to any categorical value is calculated as the ratio of overall efficiency and efficiency calculated with similar categorical Decision-Making Units (DMUs) only. The impact of both the categorical variables, affiliation to university and geographical presence, has been analyzed through the hypothesis testing with the null hypothesis that there is no impact of category on the efficiency of DMUs due to a categorical variable.
\end{abstract}

Keywords- DEA, Efficiency, Categorical variables, Higher education.

\section{Introduction}

Based on the idea of productive efficiency of Farrell (1957), Charnes et al. (1978) introduced the methodology of Data Envelopment Analysis (DEA) to evaluate the efficiency of decision-making units (DMUs) having multiple inputs and outputs. CCR models (Charnes et al., 1978) considered the production technology as a constant return to scale, and the efficiency measured was radial. Banker et al. (1984) developed the BCC models, which consider variable returns to scale. Subsequently, various models were introduced, such as SBM (Tone, 2001), additive model (Charnes et al., 1985), etc. DEA models were further extended to analyze various aspects of efficiency, such as cross-efficiency (Sexton et al., 1986), super-efficiency (Andersen and Petersen, 1993), returns to scale (Banker, 1984; Banker et al., 2004). DEA is a widely used research tool to evaluate efficiency in many sectors, for example, agriculture (Atici and Podinovski, 2015), sports (Singh, 2011; Li et al., 2015), education (Singh and Ranjan, 2018), transportation (Saxena, 2019), production control (Gholizadeh and Fazlollahtabar, 2019), among others. This paper applies the works of Johnes $(2006 \mathrm{~b})$ and Kao $(1998,2000)$ to find the impact of the second-level category on the efficiency of higher education institutions. The extended models are applied to evaluate the efficiency of colleges of Bihar, a state in India, and the impact of two categories 'affiliation to university and 'location' on the efficiency obtained. 


\subsection{Motivation}

This research is motivated by the interest in the efficiency evaluation of higher education institutions. We apply the categorical DEA to measure the efficiency of colleges in Bihar, one of the largest states in India. Different states of India have different levels of development. Bihar is on the lower side of educational parameters than some of its counterparts. For Bihar, GER ${ }^{1}$ and $\mathrm{CD}^{2}$ are 11.2 and 6.3 respectively, whereas the national figures are 21.1 and 25.3 respectively (MHRD, 2015). GER and CD measure the access to higher education. These two parameters are also crucial to policymakers. The central government targets for increment in GER by increasing the number of colleges in regions with low $\mathrm{CD}$ and by the capacity expansion of existing colleges. XII Five Year Plan (Planning Commission, 2013) targeted GER of 25.2 in 2016-17 from 17.9 in 2011-12. RUSA (MHRD, 2013) provides support to existing HEIs and to sets up new HEIs.

Efficiencies of constituent colleges are evaluated using the DEA approach, and it is observed that colleges' efficiency varies across universities. It varies from average efficiency of 0.1927 for colleges of Tilka Manjhi Bhagalpur University to 0.7043 for Jai Prakash University. It leads to the query that 'do efficiency of colleges are influenced by some factor other than college-specific.' University management can influence the performance of its colleges, for example, timeliness of examinations and results, policy on staff, etc. These types of influences are treated as 'impact of university factor.' The other factor that is considered here is the college's location, i.e., rural or urban. Colleges located in rural areas attract the majority of their students from their surrounding area only. In contrast, colleges from urban areas attract students from all over the district and, in some cases, from outside districts. The number of colleges in the urban area is more than that the rural area. In the proposed study, the efficiency of these colleges has been evaluated and analyzed for two categorical variables, the university they belong to and their location.

\subsection{Use of Categorical Variables in DEA}

In DEA, all DMUs are considered homogeneous and operating in a similar environment, and inputoutput data of DMUs are assumed to be ordinal. Initially, Banker and Morey (1986) considered categorical variables in the form of an ordered category. In this methodology, Banker and Morey divided the population of cities (one of the four inputs of DMU in the concerned empirical illustration) into hierarchical groups. For evaluating efficiency, peer DMUs from groups with same or lower population ranges only were considered. In this way, a DMU from the largest population range was assessed against all DMUs, while a DMU from the smallest population range was evaluated against all DMUs from the same range only. Cook et al. (1998) divided DMUs into multilevel groups. DMU-specific efficiency was assessed by considering the 'DMU specific input and output' of peer DMUs from the same groups. Group level efficiency was measured by considering group-specific input and output along with member DMUs' input and output, and it was compared with other groups. Førsund (2002) discussed a model in which non-zero input and output of observed DMU were compared with peer DMUs. The presence of zero input and output makes different categories of DMU. Cooper et al. (2007) presented an empirical illustration of noncontrollable categorical DMUs, where 23 DMUs are categorized into three hierarchical groups. Cooper et al. (2007) also discussed an algorithm for efficiency evaluation of controllable categorical DMUs, where DMUs can change the category. Du et al. (2015) and Kao (2009) merged

\footnotetext{
${ }^{1}$ Gross Enrollment Ratio is the number of people enrolled in higher education institutions for every 100 people of 18-23 years age.

${ }^{2}$ College Density is the number of colleges for 100 thousand people of 18-23 years age.
} 
all DMUs of a category into one unit and analyzed the efficiency of merged units and DMUs. In the research works by Johnes (2006b) and Kao (1998, 2000), DMUs belong to one of several categories, and the efficiency of a DMU is decomposed into two efficiencies, the first one is the efficiency of the DMU and the second one is due to the impact of the group. Kao (1998) evaluates the 'within DMU' efficiency of a production unit by comparing production units within DMU only and the 'among DMU' efficiency of a sub-unit by comparing sub-units among all DMUs. The ratio of 'among DMU' and 'within DMU' efficiency is taken as the 'DMU' efficiency of the respective sub-unit. Finally, the efficiency of a DMU is calculated as the average of the 'DMU' efficiencies of its sub-units.

\subsection{Application of DEA in Higher Education}

DEA has been applied across the world to evaluate efficiency in the higher education sector, such as USA (Ray and Jeon, 2008), Canada (McMillan and Datta, 1998), Mexico (Sagarra et al., 2017), UK (Thanassoulis et al., 2011), Italy (Agasisti and Ricca, 2016), Spain (Ruiz et al., 2015), Greece (Thanassoulis et al., 2017), Taiwan (Kao and Hung, 2008), China (Johnes and Yu, 2008), Australia (Abbott and Doucouliagos, 2003), etc. There are numerous DEA applications in higher education within India (Tyagi et al., 2009; Sahoo et al., 2017; Jauhar et al., 2018; Singh and Ranjan, 2018). No such study is found in the context of higher education in Bihar.

Selection of DMUs varies as research query of researchers, for example, the efficiency of university (Athanassopoulos and Shale, 1997; Abbott and Doucouliagos, 2003; Johnes, 2006a; Johnes and Yu, 2008; Ruiz et al., 2015), the efficiency of a department within a university (Sinuany-Stern et al., 1994; Kao and Hung, 2008; Tyagi et al., 2009; Jauhar et al., 2018), department efficiency across universities (Beasley, 1990, 1995; Johnes, 2006b), the efficiency of individual student or teacher (Johnes, 2006b; Sahoo et al., 2017).

Researchers evaluated different types of efficiency for measuring various aspects of higher education institutions, such as cost efficiency (Athanassopoulos and Shale, 1997; Giménez and Martínez, 2006; Thanassoulis et al., 2011), research efficiency (Beasley, 1995; Kocher et al., 2006; Sahoo et al., 2017), teaching efficiency (Beasley, 1995; Johnes, 2006b; Ruiz et al., 2015), feepaying enrollment efficiency (Avkiran, 2001). The selection of inputs and outputs are discussed in Subsection 3.2.

\section{Methodology}

In DEA, DMUs are considered to be similar, i.e., producing similar outputs from similar inputs and operating in the same environment. It is expected that no other factors are influencing their production process. If there is any other influencing factor, then that has to be taken into consideration. There are many research works on categorical variables (Banker and Morey, 1986; Cooper et al., 2007), but all of these consider preferential categorical variables. For example, the locality population (input for a DMU) is categorized into various ranges, and these ranges are ordered. Location was divided into three categories and arranged in order. However, these categories are not considered as an input or output but affected the selection of peer DMUs for efficiency evaluation. In a research paper, Beasley (1995) considered four outputs as categorical variables and provided dummy variables ${ }^{3}$. Since input values can't be equal to zero, the same approach can’t be applied to categorical input values.

\footnotetext{
${ }^{3} 1-0-0-0,0-1-0-0,0-0-1-0$, and $0-0-0-1$ were used as outputs of four respective categories.
} 
In this study, there are two factors, which could affect their production process, university (these colleges belong to) and location (rural or urban). Neither of these factors is preferential, i.e., universities can't be arranged in order nor location. Following the models presented by Johnes (2006b) and Kao $(1998,2000)$, the efficiency of college has been decomposed into two parts, i) efficiency due to its operation and ii) efficiency due to a categorical variable. The second part of the efficiency of colleges belonging to that category is averaged to get the efficiency due to the respective category. Let us assume the efficiency of any college $Z$, when compared against all colleges, is 0.72 . The efficiency of the same college $Z$, when compared against colleges of the same category (rural, assume), is 0.80 . The efficiency of college $\mathrm{Z}$ due to its operation is 0.80 , and the component of efficiency due to its presence in the rural area is 0.90 .

In Figure 1, PQRS is the efficiency frontier of colleges within a category only, and P'Q'R'S' is the efficiency frontier of all collages. The efficiency of college $\mathrm{D}$ in overall comparison is AT'/AD, and the efficiency of college $\mathrm{D}$ due to its operation is AT/AD. Component of efficiency due to the presence in the category is $(\mathrm{AT} / \mathrm{AD}) /(\mathrm{AT} / \mathrm{AD})=\mathrm{AT} / \mathrm{AT}$.

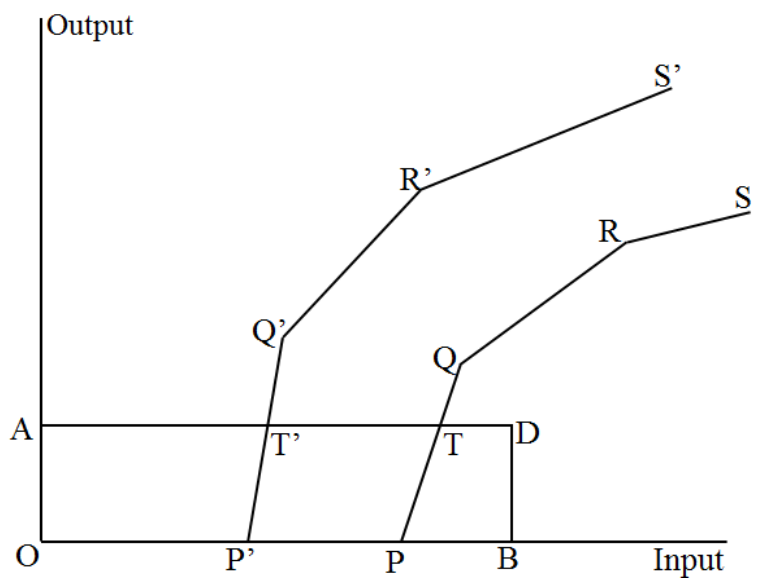

Figure 1. Comparison of efficiency frontier of a category (PQRS) with that of all colleges (P'Q'R'S').

Consider:

$j$ : variable for DMU $, j=1,2, \ldots \ldots, n, \quad k$ : fixed index for DMU to be evaluated, $i$ : variable for input, $i=1,2, \ldots \ldots, m, \quad r$ : variable for output, $r=1,2, \ldots \ldots, s$, $x_{i j}$ : the $i^{\text {th }}(i=1,2, \ldots \ldots, m)$ input of the $j^{\text {th }}(j=1,2, \ldots \ldots, n)$ DMU, $y_{r j}$ : the $r^{\text {th }}(r=1,2, \ldots \ldots, s)$ output of the $j^{\text {th }}(j=1,2, \ldots \ldots, n)$ DMU.

The set of all DMU, $\{1,2, \ldots \ldots, n\}$, is partitioned into seven subsets such that each subset contains DMUs belonging to one of the seven universities, respectively.

$\{1,2, \ldots \ldots, n\}=B B \cup T M \cup M B \cup L M \cup J P \cup B M \cup V S$, where,

$B B=\{j \mid j$ belongs to BBAB Univetsity $\}, \quad T M=\{j \mid j$ belongs to TMB Univetsity $\}$,

$M B=\{j \mid j$ belongs to MBG Univetsity $\}, \quad L M=\{j \mid j$ belongs to LNM Univetsity $\}$,

$J P=\{j \mid j$ belongs to JP Univetsity $\}, \quad B M=\{j \mid j$ belongs to BNM Univetsity $\}$, and

$V S=\{j \mid j$ belongs to VKS Univetsity $\}$. 
Similarly, The set of all DMUs, $\{1,2, \ldots \ldots, n\}$, is partitioned into two subsets such that each subset contains DMUs belonging to one of the rural and urban locations, respectively.

$\{1,2, \ldots \ldots, n\}=R L \cup U B$, where,

$R L=\{j \mid j$ belongs to the rural location $\}$ and $U B=\{j \mid j$ belongs to the urban location $\}$.

Model for efficiency of $k^{\text {th }}$ college overall:

Min $E$

s.t. $\quad E x_{i k}-\sum_{j=1}^{n} \lambda_{j} x_{i j} \geq 0, \quad \forall i=1,2, \ldots, m$,

$\sum_{j=1}^{n} \lambda_{j} y_{r j} \geq y_{r k}, \quad \forall r=1,2, \ldots, s$,

$\lambda_{j} \geq 0, \quad \forall j=1,2, \ldots \ldots, n$.

$E$ is affected by the inefficiency of DMU-specific factors and two factors, university and location. Colleges affiliated with the same university are considered as peer DMUs to remove the impact of university factors on the efficiency of DMU. Model for efficiency of $k^{\text {th }}$ college within university $U$ only:

Min $E^{U}$

s.t. $\quad E^{U} x_{i k}-\sum_{j \in U} \lambda_{j} x_{i j} \geq 0, \forall i=1,2, \ldots, m$,

$\sum_{j \in U} \lambda_{j} y_{r j} \geq y_{r k}, \forall r=1,2, \ldots, s$,

$\lambda_{j} \geq 0, \quad \forall j \in U$.

Similarly, to remove the impact of location factor on the efficiency of DMU, colleges belonging to the same location are considered as peer DMUs. Model for efficiency of $k^{\text {th }}$ college within specific location $A$ only:

Min $E^{A}$

s.t. $\quad E^{A} x_{i k}-\sum_{j \in A} \lambda_{j} x_{i j} \geq 0, \forall i=1,2, \ldots, m$,

$\sum_{j \in A} \lambda_{j} y_{r j} \geq y_{r k}, \forall r=1,2, \ldots, s$,

$\lambda_{j} \geq 0, \forall j \in A$.

Colleges affiliated to the same university and belonging to the same area are considered as peer DMUs to remove the impact of university factor and location factor on the efficiency of DMU. Model for efficiency of $k^{\text {th }}$ college within specific location $A$ and university $U$ only:

Min $E^{U \cap A}$

s.t. $\quad E^{U \cap A} x_{i k}-\sum_{j \in U \cap A} \lambda_{j} x_{i j} \geq 0, \quad \forall i=1,2, \ldots, m$,

$\sum_{j \in U \cap A} \lambda_{j} y_{r j} \geq y_{r k}, \forall r=1,2, \ldots, s$,

$\lambda_{j} \geq 0, \quad \forall j \in U \cap A$.

$E^{U \cap A}$ is college efficiency due to its factor, whereas the efficiency score $E$ is affected by efficiency due to the university factor and location factor. $E$ can be decomposed into two parts $E^{U}$ and $E / E^{U}$. The first part is efficiency after removing the impact of the university factor (all peer DMUs are colleges from the same university only), and the latter part is the factor of efficiency due to the university category. In another decomposition, $E$ can be decomposed into two parts $E^{A}$ and $E / E^{A}$. The first part is efficiency after removing the impact of location factor (all peer DMUs are colleges from the same location only), and the latter part is the factor of efficiency due to location category. Further, $E^{U}$ is free from university factors only, i.e., all colleges of the same university are on the 
peer list in this evaluation. Hence, the impact of location factor on efficiency $E^{U}$ is $E^{U} / E^{U \cap A}$. Similarly, $E^{A}$ is free from location factor only, i.e., all colleges from the same location are in the peer list in this evaluation. Hence, the impact of location factor on efficiency $E^{A}$ is $E^{A} / E^{U \cap A}$. Finally, the impact of both factors on $E$, the efficiency of college, is $E / E^{U \cap A}$, which can be calculated in two ways, either by multiplying $E / E^{U}$ and $E^{U} / E^{U \cap A}$ or multiplying $E / E^{A}$ and $E^{A} / E^{U \cap A}$.

Next, the application of the proposed methodology is discussed.

\section{Application}

\subsection{Higher Education in India and Bihar}

Higher education institutions are of three types, university, college, and stand-alone institution. Universities are either set up by parliament (central university, institute of national importance, and other institutes managed by central government) or set up by respective state legislatures (state public universities and state private universities) and institutes accorded the status of deemed-tobe-university. In India, all colleges are affiliated with any of the state public universities. Based on the level of affiliation, they are classified into constituent colleges or affiliated colleges. Constituent colleges are units of state public universities and are managed by respective universities in all aspects, such as academic, conduction of examination, recruitment of staffs, financial matters, etc. Affiliated colleges are affiliated with one of the state public universities only for academic, examination, and degree purposes. The remaining HEIs are stand-alone institutions, and they are neither established by any act nor accorded the status of deemed-to-be-university nor affiliated to any established university. These SAIs are granted the power to grant diplomas only and are subject to regulatory bodies such as the All India Council for Technical Education.

Among 22 universities in Bihar, three are central universities; three institutes of national importance, one national law university, one international university, one deemed-to-be-university, five specialized state public universities (one each of Agriculture, Sanskrit Language, Arabic, and Persian Language, Technical, and Open), and eight state public university. The latter mentioned eight universities provide courses in humanities, sciences, and commerce. In Bihar, $84.4 \%$ of total students enrolled in higher education are enrolled at colleges (MHRD, 2015). The whole geographic area of Bihar is divided into seven parts; each part is the territory of one university; colleges are affiliated to the respective university. The only exception is Patna University which is located in Patna capital city and having only ten selected colleges. The remaining colleges of the city of Patna are affiliated with Magadh University. Each of the seven universities functions through university departments, constituent colleges, and affiliated colleges. University departments of state public universities do not provide undergraduate courses. It is worth mentioning that the state public universities of Bihar receive financial support from government sources ${ }^{4}$. This includes complete financial support to constituent colleges also. Income (tuition fee, examination fee, etc.) of constituent colleges and state public universities is a small portion of their expenditure. Affiliated colleges lack such financial support. Since constituent colleges receive funds from the government, they are responsible for fulfilling the objectives for which they are established.

\footnotetext{
${ }^{4}$ Government of Bihar, and University Grants Commission (agency of Ministry of Education, Government of India).
} 


\subsection{Dataset, Input, and Output}

There are a total of 223 constituent colleges of the seven state public universities of Bihar. These colleges provide courses in humanities, science, and commerce only. Out of all the 223 colleges, data were available only for 147 colleges which is consistent with the application of the DEA model. ${ }^{5 \& 6}$ Table 1 shows the university-wise number of colleges. DEA practitioners considered various inputs and outputs, for example, number of teaching staff, general expenditure, floor area, number of books in the library, etc. as inputs, and number of students taught, research publication, research income, etc. as outputs ( Beasley, 1990; Abbott and Doucouliagos, 2003; Johnes and Yu, 2008; Kao and Hung, 2008; Agasisti and Johnes, 2009; Sahoo et al., 2017; Thanassoulis et al., 2011, 2017). For the present study, inputs considered are the number of senior teaching staffs (Professors and Associate Professors), the number of junior teaching staffs (Assistant Professors and other teaching staffs), and the number of non-teaching staffs; outputs considered are the number of students enrolled in undergraduate programs, and the number of students enrolled in postgraduate programs. Summary statistics of the dataset are mentioned in Table 2.

Table 1. Seven state public universities and the number of colleges considered for the study.

\begin{tabular}{|l|c|}
\hline \multicolumn{1}{|c|}{ University } & Number of colleges \\
\hline BBAB University: Babasaheb Bhimrao Ambedkar Bihar University, Muzaffarpur & 26 \\
\hline TMB University: Tilka Manjhi Bhagalpur University, Bhagalpur & 9 \\
\hline MBG University: Magadh University, Bodh-Gaya & 26 \\
\hline LNM University: Lalit Narayan Mithila University, Darbhanga & 35 \\
\hline JP University: Jai Prakash University, Chapra & 11 \\
\hline BNM University: Bhupendra Narayan Mandal University, Madhepura & 23 \\
\hline VKS University: Veer Kunwar Singh University, Ara & 17 \\
\hline
\end{tabular}

*Number of constituent colleges only, having non-zero inputs and no outlier input-output data.

Table 2. Summary statistics of input and output data of 147 colleges.

\begin{tabular}{|c|c|c|c|c|c|}
\hline & $\begin{array}{c}\text { Number of Professors } \\
\text { and Associate Professors }\end{array}$ & $\begin{array}{c}\text { Number of Assistant } \\
\text { Professors and others }\end{array}$ & $\begin{array}{c}\text { Number of non- } \\
\text { teaching staffs }\end{array}$ & $\begin{array}{c}\text { Students enrolled } \\
\text { in PG courses }\end{array}$ & $\begin{array}{c}\text { Students enrolled } \\
\text { in UG courses }\end{array}$ \\
\hline Mean & 19.86 & 13.56 & 40.00 & 220.87 & 2913.95 \\
\hline $\begin{array}{c}\text { Standard } \\
\text { Deviation }\end{array}$ & 17.97 & 20.38 & 26.28 & 499.21 & 1645.12 \\
\hline Median & 14 & 8 & 34 & 0 & 2640 \\
\hline Minimum & 1 & 1 & 5 & 0 & 236 \\
\hline Maximum & 107 & 152 & 144 & 3118 & 9847 \\
\hline Sum & 2919 & 1993 & 5880 & 32468 & 428351 \\
\hline
\end{tabular}

\subsection{Efficiency Evaluation of all Colleges and Decomposition of Efficiency}

The efficiencies of all 147 DMUs are evaluated through all four models (1-4). These efficiency scores are given in columns 2, 3, 5, and 7 in Table 3 for colleges of LNM University ${ }^{7}$. The details are as follows:

(i) second column: efficiency of the college when all colleges are considered in the peer group,

(ii) third column: efficiency of the college when all colleges of the same university are considered in the peer group,

(iii) fifth column: efficiency of the college when all colleges of the same location are considered in the peer group,

\footnotetext{
${ }^{5}$ Data source: government web portal data.gov.in.

${ }^{6}$ Colleges with zero input data and outlier data Pastor et al. (1999) are not considered.

${ }^{7}$ Similar datasets of other universities are omitted.
} 
Ranjan \& Singh: Efficiency Analysis of Higher Education Institutions: Use of Categorical ...

(iv) seventh column: efficiency of the college when all colleges of the same university and the same location are considered in the peer group.

Impacts of the categories on the efficiency of college are calculated as discussed in Section 2.

Columns 4, 6, 8, 9, and 10 of Table 3 provide the impact of categories as shown below:

(i) fourth column: impact on $E$ due to university category,

(ii) sixth column: impact on $E$ due to location category,

(iii) eighth column: impact on $E^{U}$ due to location category,

(iv) ninth column: impact on $E^{A}$ due to university category,

(v) tenth column: impact on $E$ due to both categories.

A similar dataset can be obtained for other universities also.

Table 3. Efficiencies of colleges of LNM University.

\begin{tabular}{|c|c|c|c|c|c|c|c|c|c|}
\hline DMU & $E$ & $E^{L M}$ & $\frac{E}{E^{L M}}$ & $E^{R L}$ & $\frac{E}{E^{R L}}$ & $E^{L M \cap R L}$ & $\frac{E^{L M}}{E^{L M \cap R L}}$ & $\frac{E^{R L}}{E^{L M \cap R L}}$ & $\frac{E}{E^{L M \cap R L}}$ \\
\hline 510 & 0.0584 & 0.0586 & 0.9960 & 0.0585 & 0.9982 & 0.0586 & 1.0000 & 0.9979 & 0.9960 \\
\hline 511 & 0.1330 & 0.1412 & 0.9416 & 0.1330 & 1.0000 & 0.1412 & 1.0000 & 0.9416 & 0.9416 \\
\hline 516 & 0.6459 & 0.7434 & 0.8689 & 0.6620 & 0.9757 & 0.7434 & 1.0000 & 0.8905 & 0.8689 \\
\hline 517 & 0.2843 & 0.3003 & 0.9465 & 0.2843 & 1.0000 & 0.3003 & 1.0000 & 0.9465 & 0.9465 \\
\hline 520 & 0.4855 & 0.5726 & 0.8479 & 0.4986 & 0.9738 & 0.5726 & 1.0000 & 0.8707 & 0.8479 \\
\hline 521 & 0.1343 & 0.1575 & 0.8527 & 0.1373 & 0.9781 & 0.1575 & 1.0000 & 0.8717 & 0.8527 \\
\hline 522 & 0.3390 & 0.3958 & 0.8565 & 0.3446 & 0.9837 & 0.3958 & 1.0000 & 0.8707 & 0.8565 \\
\hline 523 & 1 & 1 & 1 & 1 & 1.0000 & 1 & 1.0000 & 1.0000 & 1.0000 \\
\hline 525 & 0.3481 & 0.3657 & 0.9520 & 0.3481 & 1.0000 & 0.3657 & 1.0000 & 0.9520 & 0.9520 \\
\hline 526 & 0.1255 & 0.1380 & 0.9099 & 0.1255 & 1.0000 & 0.1380 & 1.0000 & 0.9099 & 0.9099 \\
\hline 527 & 0.6650 & 0.7076 & 0.9399 & 0.9811 & 0.6779 & 0.9811 & 0.7212 & 1.0000 & 0.6779 \\
\hline 528 & 0.7234 & 1 & 0.7234 & 0.8184 & 0.8839 & 1 & 1.0000 & 0.8184 & 0.7234 \\
\hline 529 & 0.2560 & 0.2585 & 0.9902 & 0.2560 & 1.0000 & 0.2585 & 1.0000 & 0.9902 & 0.9902 \\
\hline 531 & 0.3115 & 0.3558 & 0.8757 & 0.3115 & 1.0000 & 0.3558 & 1.0000 & 0.8757 & 0.8757 \\
\hline 532 & 0.8419 & 1 & 0.8419 & 0.9075 & 0.9278 & 1 & 1.0000 & 0.9075 & 0.8419 \\
\hline 533 & 1 & 1 & 1 & 1 & 1.0000 & 1 & 1.0000 & 1.0000 & 1.0000 \\
\hline 534 & 0.3118 & 0.3861 & 0.8076 & 0.3421 & 0.9115 & 0.3861 & 1.0000 & 0.8860 & 0.8076 \\
\hline 536 & 0.2234 & 0.2530 & 0.8827 & 0.2244 & 0.9952 & 0.2530 & 1.0000 & 0.8870 & 0.8827 \\
\hline 537 & 0.1974 & 0.2198 & 0.8984 & 0.1975 & 0.9999 & 0.2198 & 1.0000 & 0.8985 & 0.8984 \\
\hline 538 & 0.1604 & 0.1675 & 0.9579 & 0.1630 & 0.9843 & 0.1675 & 1.0000 & 0.9732 & 0.9579 \\
\hline \multicolumn{3}{|c|}{ Sub average } & 0.9045 & & 0.9645 & & 0.9861 & 0.9244 & 0.8914 \\
\hline DMU & $E$ & $E^{L M}$ & $\frac{E}{E^{L M}}$ & $E^{U B}$ & $\frac{E}{E^{U B}}$ & $E^{L M \cap U B}$ & $\frac{E^{L M}}{E^{L M \cap U B}}$ & $\frac{E^{U B}}{E^{L M \cap U B}}$ & $\frac{E}{E^{L M \cap R B}}$ \\
\hline 501 & 0.6444 & 0.6545 & 0.9846 & 0.6581 & 0.9791 & 0.7030 & 0.9310 & 0.9362 & 0.9167 \\
\hline 502 & 0.1320 & 0.1347 & 0.9798 & 0.1478 & 0.8927 & 0.1548 & 0.8700 & 0.9549 & 0.8525 \\
\hline 504 & 0.3474 & 0.3897 & 0.8914 & 0.4210 & 0.8251 & 0.5406 & 0.7208 & 0.7788 & 0.6426 \\
\hline 505 & 0.3273 & 0.3537 & 0.9254 & 0.3665 & 0.8929 & 0.4254 & 0.8312 & 0.8614 & 0.7692 \\
\hline 506 & 0.1322 & 0.1502 & 0.8806 & 0.2674 & 0.4945 & 0.3039 & 0.4941 & 0.8799 & 0.4351 \\
\hline 507 & 0.0832 & 0.0938 & 0.8875 & 0.1319 & 0.6309 & 0.1476 & 0.6351 & 0.8935 & 0.5637 \\
\hline 508 & 0.1358 & 0.1643 & 0.8262 & 0.1869 & 0.7265 & 0.2346 & 0.7004 & 0.7965 & 0.5786 \\
\hline 509 & 0.1050 & 0.1193 & 0.8805 & 0.1188 & 0.8840 & 0.1666 & 0.7158 & 0.7129 & 0.6303 \\
\hline 514 & 1 & 1 & 1 & 1 & 1.0000 & 1 & 1.0000 & 1.0000 & 1.0000 \\
\hline 515 & 0.4738 & 0.5404 & 0.8767 & 0.5532 & 0.8564 & 0.7569 & 0.7140 & 0.7309 & 0.6260 \\
\hline 519 & 0.1953 & 0.2220 & 0.8795 & 0.2889 & 0.6760 & 0.5489 & 0.4045 & 0.5263 & 0.3558 \\
\hline 530 & 0.2051 & 0.2342 & 0.8757 & 0.3259 & 0.6294 & 0.3888 & 0.6024 & 0.8381 & 0.5275 \\
\hline 539 & 0.5462 & 0.6466 & 0.8447 & 0.8687 & 0.6287 & 1 & 0.6466 & 0.8687 & 0.5462 \\
\hline 540 & 0.5872 & 0.6204 & 0.9465 & 1 & 0.5872 & 1 & 0.6204 & 1.0000 & 0.5872 \\
\hline 541 & 0.6429 & 0.7211 & 0.8916 & 0.9233 & 0.6963 & 1 & 0.7211 & 0.9233 & 0.6429 \\
\hline \multicolumn{3}{|c|}{ Sub average } & 0.9047 & & 0.7600 & & 0.7072 & 0.8468 & 0.6449 \\
\hline \multicolumn{3}{|c|}{ Overall average } & 0.9046 & & & & & & \\
\hline
\end{tabular}


The following section discusses the results obtained.

\section{Result and Discussion}

University-wise averages of $E, E^{U}$, and $E / E^{U}$ for all colleges in a university are compiled in Table 4. The average impact of university factor on $E$ for every university, $E / E^{U}$, is tested statistically against the null hypothesis that the average impact is 0.95 or more ${ }^{8}$. Closeness to 1 denotes lesser impact, and closeness to 0 denotes higher impact on efficiency. The standard deviation of $E / E^{U}$ for every university and the corresponding $p$-value of the test is also shown in Table 4 . It is found that the average impact is not significant for JP University and is significant for all other universities. When the average impacts of university factors are segregated by rural and urban areas, then still results are same, i.e., colleges of both areas of six universities (except JP University) have the impact of university factor on their efficiency. The first column of each location in Table 5 represents the average impact of university factor on $E$, overall efficiency, of colleges of the specific area (rural or urban) of that university. For example, the average impact of the university factor on $E$ of rural colleges of BBAB University is 0.5474 . Respective standard deviation and $p$ value can be found just below the average figure in the same column. The next column of each location represents the average impact of the location of the college on $E^{U}$. For example, 0.7639 is the impact of rural areas on the efficiency of colleges when colleges of BBAB University only are compared. It is observed that rural area has an impact on colleges of only one university, i.e., BBAB University, and the urban area has an impact on MBG University, LNM University, and BNM University.

Similar to Table 4, an average of $E, E^{A}$, and $E / E^{A}$ for every location are given in Table 6. Its fourth column represents the average impact of location factor on $E$, overall efficiency, of colleges of that location. Impacts of urban location are found to be significant. When the average impact of location factor on $E$ is segregated by universities, urban colleges of all universities except JP University are impacted by urban factor. The first row for each university in Table 7 represents the average impact of location factor on colleges of the specific university of that location. For example, the average impact of location factor on $E$ of rural colleges of BBAB University is 0.9796. Respective standard deviation and $p$-value follow the average figure in the same row. The next row for each university represents the average impact of university factors on $E^{A}$. It is observed that six universities (except JP University) have an impact on $E^{A}$ of colleges from an urban location. ${ }^{9}$

Table 4. The average impact of university factor and its significance.

\begin{tabular}{|c|c|c|c|c|c|}
\hline \multirow{2}{*}{ University } & \multirow{2}{*}{$\boldsymbol{E}$ Average } & \multirow{2}{*}{$\boldsymbol{E}^{\boldsymbol{U}}$ Average } & \multicolumn{3}{|c|}{$\boldsymbol{E} / \boldsymbol{E}^{\boldsymbol{U}}$} \\
\cline { 4 - 6 } & & & Average & SD & p-value \\
\hline BBAB & 0.4768 & 0.6990 & 0.6700 & 0.2067 & $0.0000^{*}$ \\
\hline TMB & 0.1927 & 0.7856 & 0.2390 & 0.0806 & $0.0000^{*}$ \\
\hline MBG & 0.2800 & 0.6137 & 0.4396 & 0.1221 & $0.0000^{*}$ \\
\hline LNM & 0.3944 & 0.4362 & 0.9046 & 0.0636 & $0.001^{*}$ \\
\hline JP & 0.7043 & 0.7689 & 0.9227 & 0.1612 & 0.2935 \\
\hline BNM & 0.4142 & 0.5342 & 0.7732 & 0.1642 & $0.0000^{*}$ \\
\hline VKS & 0.4716 & 0.7849 & 0.6012 & 0.1981 & $0.0000^{*}$ \\
\hline
\end{tabular}

* significant

${ }^{8}$ If we check against 1 , then there are examples that 0.9895 comes to be significantly less than 1 , which is true theoretically, but practically impact of 0.9895 is negligible, hence we consider 0.95 as the threshold to have an impact on efficiency.

${ }^{9}$ Since the rural factor does not have an impact on $E$, rural location is not considered here. 
Table 5. The average impact of location factor on $E^{U}$ and its significance.

\begin{tabular}{|c|c|c|c|c|c|c|c|}
\hline & \multicolumn{3}{|c|}{ Rural } & \multicolumn{3}{|c|}{ Urban } \\
\hline & & $E / E^{U}$ & $E^{U} / E^{U \cap R L}$ & $E / E^{U \cap R L}$ & $E / E^{U}$ & $E^{U} / E^{U \cap U B}$ & $E / E^{U \cap U B}$ \\
\hline \multirow{3}{*}{ BBAB } & Avg & 0.5474 & 0.7639 & \multirow{3}{*}{0.4001} & 0.7245 & 0.9895 & \multirow{3}{*}{0.7193} \\
\hline & SD & 0.1532 & 0.1820 & & 0.2072 & 0.0218 & \\
\hline & p-value & $0.0001^{*}$ & $0.0116^{*}$ & & $0.0001^{*}$ & 1.0000 & \\
\hline \multirow{3}{*}{ TMB } & Avg & 0.2848 & 0.7772 & \multirow{3}{*}{0.2340} & 0.2024 & 0.9293 & \multirow{3}{*}{0.1876} \\
\hline & SD & 0.0940 & 0.2509 & & 0.0509 & 0.0715 & \\
\hline & p-value & $0.0004 *$ & 0.1311 & & $0.0000^{*}$ & 0.2762 & \\
\hline \multirow{3}{*}{ MBG } & Avg & 0.4232 & 0.9901 & \multirow{3}{*}{0.4178} & 0.4517 & 0.9068 & \multirow{3}{*}{0.4178} \\
\hline & SD & 0.1142 & 0.0328 & & 0.1301 & 0.0780 & \\
\hline & p-value & $0.0000^{*}$ & 0.9989 & & $0.0000^{*}$ & $0.0251 *$ & \\
\hline \multirow{3}{*}{ LNM } & Avg & 0.9045 & 0.9861 & \multirow{3}{*}{0.8914} & 0.9047 & 0.7072 & \multirow{3}{*}{0.6449} \\
\hline & SD & 0.0727 & 0.0623 & & 0.0515 & 0.1565 & \\
\hline & $\mathrm{p}$-value & $0.0057^{*}$ & 0.9910 & & $0.0021^{*}$ & $0.0000^{*}$ & \\
\hline \multirow{3}{*}{ JP } & Avg & 0.8965 & 0.9992 & \multirow{3}{*}{0.8957} & 0.9686 & 0.8453 & \multirow{3}{*}{0.8197} \\
\hline & SD & 0.1982 & 0.0022 & & 0.0598 & 0.1098 & \\
\hline & $\mathrm{p}$-value & 0.2511 & 1.0000 & & 0.7109 & 0.0762 & \\
\hline \multirow{3}{*}{ BNM } & Avg & 0.7381 & 0.9622 & \multirow{3}{*}{0.7130} & 0.7958 & 0.7695 & \multirow{3}{*}{0.6032} \\
\hline & SD & 0.1538 & 0.1133 & & 0.1722 & 0.1984 & \\
\hline & $\mathrm{p}$-value & $0.0016^{*}$ & 0.6230 & & $0.0026^{*}$ & $0.0023^{*}$ & \\
\hline \multirow{3}{*}{ VKS } & Avg & 0.6752 & 0.9952 & \multirow{3}{*}{0.6725} & 0.5704 & 0.9085 & \multirow{3}{*}{0.5229} \\
\hline & SD & 0.2056 & 0.0108 & & 0.1954 & 0.0945 & \\
\hline & p-value & $0.0202 *$ & 0.9996 & & $0.0000^{*}$ & 0.0782 & \\
\hline
\end{tabular}

* significant

Table 6. The average impact of location factor and its significance.

\begin{tabular}{|c|c|c|c|c|c|}
\hline \multirow{2}{*}{ Location } & \multirow{2}{*}{ EAverage } & \multirow{2}{*}{$\boldsymbol{E}^{\boldsymbol{A}}$ Average } & \multicolumn{3}{|c|}{$\boldsymbol{E} / \boldsymbol{E}^{\boldsymbol{A}}$} \\
\cline { 4 - 6 } & & Average & SD & p-value \\
\hline Rural & 0.4112 & 0.4296 & 0.9729 & 0.0716 & 0.9935 \\
\hline Urban & 0.4119 & 0.5340 & 0.7596 & 0.1707 & $0.0000^{*}$ \\
\hline
\end{tabular}

Table 7. The average impact of university factor on $E^{A}$ and its significance.

\begin{tabular}{|c|c|c|c|c|c|c|c|}
\hline & & \multicolumn{3}{|c|}{ Rural } & \multicolumn{3}{|c|}{ Urban } \\
\hline & & Avg & SD & p-value & Avg & SD & p-value \\
\hline \multirow{3}{*}{$\mathrm{BBAB}$} & $E / E^{A}$ & 0.9796 & 0.0352 & 0.9756 & 0.7860 & 0.1815 & $0.0007 *$ \\
\hline & $E^{A} / E^{B B \cap A}$ & 0.4096 & 0.0782 & 0.0000 & 0.9064 & 0.1062 & $0.0499 *$ \\
\hline & $E / E^{B B \cap A}$ & \multicolumn{3}{|c|}{0.4001} & \multicolumn{3}{|c|}{0.7193} \\
\hline \multirow{3}{*}{ TMB } & $E / E^{A}$ & 0.9772 & 0.0239 & 0.9467 & 0.6089 & 0.0798 & $0.0003^{*}$ \\
\hline & $E^{A} / E^{T M \cap A}$ & 0.2421 & 0.1503 & 0.0013 & 0.3052 & 0.0563 & $0.0000 *$ \\
\hline & $E / E^{T M \cap A}$ & \multicolumn{3}{|c|}{0.2340} & \multicolumn{3}{|c|}{0.1876} \\
\hline \multirow{3}{*}{ MBG } & $E / E^{A}$ & 0.9896 & 0.0210 & 1.0000 & 0.8071 & 0.1615 & $0.0020^{*}$ \\
\hline & $E^{A} / E^{M B \cap A}$ & 0.4227 & 0.1118 & 0.0000 & 0.5050 & 0.1095 & $0.0000 *$ \\
\hline & $E / E^{M B \cap A}$ & \multicolumn{3}{|c|}{0.4178} & \multicolumn{3}{|c|}{0.4178} \\
\hline \multirow{3}{*}{ LNM } & $E / E^{A}$ & 0.9645 & 0.0752 & 0.8005 & 0.7600 & 0.1543 & $0.0001 *$ \\
\hline & $E^{A} / E^{L M \cap A}$ & 0.9244 & 0.0553 & 0.0262 & 0.8468 & 0.1247 & $0.0032 *$ \\
\hline & $E / E^{L M \cap A}$ & \multicolumn{3}{|c|}{0.8914} & \multicolumn{3}{|c|}{0.6449} \\
\hline \multirow{3}{*}{ JP } & $E / E^{A}$ & 0.9783 & 0.0407 & 0.9424 & 0.8954 & 0.0883 & 0.1522 \\
\hline & $E^{A} / E^{J \cap \cap A}$ & 0.9168 & 0.2019 & 0.3396 & 0.9161 & 0.1117 & 0.2935 \\
\hline & $E / E^{J P \cap A}$ & \multicolumn{3}{|c|}{0.8957} & \multicolumn{3}{|c|}{0.8197} \\
\hline \multirow{3}{*}{ BNM } & $E / E^{A}$ & 0.9498 & 0.1495 & 0.4984 & 0.7805 & 0.1718 & $0.0014 *$ \\
\hline & $E^{A} / E^{B M \cap A}$ & 0.7530 & 0.1523 & 0.0023 & 0.7720 & 0.1550 & $0.0004 *$ \\
\hline & $E / E^{B M \cap A}$ & \multicolumn{3}{|c|}{0.7130} & \multicolumn{3}{|c|}{0.6032} \\
\hline \multirow{3}{*}{ VKS } & $E / E^{A}$ & 0.9896 & 0.0158 & 0.9975 & 0.6534 & 0.1713 & $0.0000^{*}$ \\
\hline & $E^{A} / E^{V S \cap A}$ & 0.6790 & 0.2057 & 0.0211 & 0.7876 & 0.1866 & $0.0059^{*}$ \\
\hline & $E / E^{V S \cap A}$ & \multicolumn{3}{|c|}{0.6725} & \multicolumn{3}{|c|}{0.5229} \\
\hline
\end{tabular}


Table 8 represents the average impact of university and location on colleges belonging to a university of a specific location. For example, 0.4001 is the average impact of university and rural category on the efficiency of rural colleges from BBAB University. All such pairs of both factors are significant except those from both areas of JP University.

Table 8. The average impact of university and location factor on $E$ and its significance.

\begin{tabular}{|c|c|c|c|c|c|c|c|}
\hline & & \multicolumn{3}{|c|}{ Rural } & \multicolumn{2}{c|}{ Urban } \\
\hline & & Avg & SD & p-value & Avg & SD & p-value \\
\hline BBAB & $E / E^{B B \cap A}$ & 0.4001 & 0.0709 & $0.0000^{*}$ & 0.7193 & 0.2125 & $0.0001^{*}$ \\
\hline TMB & $E / E^{T M \cap A}$ & 0.2340 & 0.1392 & $0.0010^{*}$ & 0.1876 & 0.0498 & $0.0000^{*}$ \\
\hline MBG & $E / E^{M B \cap A}$ & 0.4178 & 0.1093 & $0.0000^{*}$ & 0.4178 & 0.1451 & $0.0000^{*}$ \\
\hline LNM & $E / E^{L M \cap A}$ & 0.8914 & 0.0880 & $0.0039^{*}$ & 0.6449 & 0.1741 & $0.0000^{*}$ \\
\hline JP & $E / E^{J P \cap A}$ & 0.8957 & 0.1979 & 0.2478 & 0.8197 & 0.1290 & 0.0683 \\
\hline BNM & $E / E^{B M \cap A}$ & 0.7130 & 0.1829 & $0.0023^{*}$ & 0.6032 & 0.1858 & $0.0000^{*}$ \\
\hline VKS & $E / E^{V S \cap A}$ & 0.6725 & 0.2076 & $0.0202^{*}$ & 0.5229 & 0.2085 & $0.0000^{*}$ \\
\hline
\end{tabular}

Following is the list of various categories and subcategories which have a significant impact.

a) First level impact of university factor on $E$ : BBAB, TMB, MBG, LNM, BNM, VKS; both subsets (rural and urban) of six universities also.

b) First level impact of area factor on $E$ : urban; six out of seven subsets (universities) of urban location also.

c) Second level impact of area factor on $E^{U}$ : rural on BBAB, urban on MBG, LNM, BNM.

d) Second level impact of university factor on $E^{A}$ : BBAB, TMB, MBG, LNM, BNM, VKS on urban.

e) Impact of both factors on $E$ : 12 of 14 subcategories except JP-urban and JP-rural.

All universities other than JP University have a significant impact on $E$. It means that the efficiency frontier made by the colleges of JP University is closer to the overall efficiency frontier. The remaining universities may look up to the functioning style/ management of the JP University to improve the university-specific factor in the efficiency of their affiliated colleges. Similarly, the impact of the urban area is significant on $E$, whereas the impact of the rural area is not significant on $E$. It may be due to the substantial migration of students from the urban area to outside. Another reason could be attributed to the excess number of colleges in the urban area.

The difference between Points $b$ and $c$ is as follows: Point $b$ takes care of the first level impact of area factor on $E$, whereas Point $c$ takes care of the second level impact of area factor on $E^{U}$. Similarly, the difference between Points $a$ and $d$ is as follows: Point $a$ takes care of the first level impact of university factor on $E$, whereas Point $d$ takes care of the second level impact of university factor on $E^{A}$.

The difference between Point $e$ and Points $c$ and $d$ is as follows: In Point $e$, the impact of both factors has been evaluated simultaneously by making 14 subcategories from seven different universities and two types of areas. Whereas in Point $c$, the second level impact of area factor on $E^{U}$ has been considered for those universities where the first level impact of university factor on $E$ was significant. Similarly, in Point $d$, the second level impact of the university factor on $E^{A}$ has been considered for those areas where the first level impact of area factor on $E$ was significant. 


\section{Conclusions}

Efficiencies of 147 colleges of Bihar have been evaluated and decomposed into efficiency within category frontier (i.e., efficiency due to DMU specific reasons) and efficiency attributable to the category (i.e., efficiency due to category-specific reasons). Two categorizations have been considered, i) university, i.e., each college is a unit of a university; hence all universities are considered as a categorical variable, and ii) location of the university, i.e., each college is located in either rural or urban area, and hence rural and urban are considered as another categorical variable. In the case of colleges of TMB University, the average efficiency attributed of the university is found to be lowest (which means more impact), where the same figure is found to be higher for colleges of JP University (which means lesser impact, and in case of JP University it is not significant). In the case of rural-urban categorization, frontiers made by rural colleges are found to be closer to the overall frontier than that of urban counterparts. The average impact of the rural factor on the efficiency of colleges is found to be not significant. In contrast, the average impact of the urban factor on the efficiency of colleges is found to be significant. Second level impact of one category on efficiency frontier of another categorization is also evaluated, for example, the impact of location factor on university-wise efficiency frontier and impact of university factor on locationwise efficiency frontier. Finally, the impact of each subcategory on the overall efficiency frontier is evaluated. It is observed that impacts of 12 subcategories, out of 14 subcategories, are significant.

Policymakers at different levels of higher education governance can use decomposed efficiency to find out reasons for its lower values. For example, depending on the lower values of $E / E^{U}$, the efficiency attributable to the university's management of its colleges, respective university administration can compare its management style/attributes with that of other universities. These university management styles/attributes may include the timely conduction of academic activities, inclusion of relevant courses, etc. Higher Education Department of Bihar can compare the difference between average efficiency attributable to rural and urban colleges by investigating the efficiency values $E / E^{R L}, E / E^{U B}, E^{U} / E^{R L}$, and $E^{U} / E^{U B}$. It is the responsibility of the State Higher Education Department to provide access to colleges to its students in an efficient manner. The possible reason behind the significant impact of the urban category could be the mass migration of urban students outside the state. The State Higher Education Department should look up to the expectation of students and should provide the necessary educational infrastructure. College administration can look for the pure efficiency value $E^{U \cap A}$ i.e., decomposed efficiency after removing the impact of both categorizations. The decision/function attributable to colleges can be conducting classes/tutorials/laboratory hours as scheduled, supporting extra-curricular activities, etc.

Since selected districts have been assigned to every university, there could be some external factors specific to that region, which can influence the performance of colleges and affect their efficiency. The migration of students outside the area may happen due to socio-economic reasons and better opportunities in the established educational hub, such as the migration to Kolkata (Calcutta University), Varanasi (Banaras Hindu University), and Delhi (the University of Delhi). While analyzing the efficiency attributable to the university category, policymakers may take care of the above-mentioned factors.

Availability of data for the remaining colleges would make the analysis complete. Availability of data on migration of students to outside the state would make the discussion more comprehensive. Along with the DEA efficiency evaluation and the decomposition of efficiency due to two factors, other statistical analyses may also be applied to the dataset to explore various outcomes. 
Conflict of Interest

The author confirms that there is no conflict of interest to declare for this publication.

\section{Acknowledgments}

This research did not receive any specific grant from funding agencies in the public, commercial, or not-for-profit sectors. The authors would like to thank the editor and anonymous reviewers for their comments that help improve the quality of this work.

\section{References}

Abbott, M., \& Doucouliagos, C. (2003). The efficiency of Australian universities: A data envelopment analysis. Economics of Education Review, 22(1), 89-97.

Agasisti, T., \& Johnes, G. (2009). Beyond frontiers: comparing the efficiency of higher education decisionmaking units across more than one country. Education Economics, 17(1), 59-79.

Agasisti, T., \& Ricca, L. (2016). Comparing the efficiency of Italian public and private universities (20072011): An empirical analysis. Italian Economic Journal, 2(1), 57-89.

Andersen, P., \& Petersen, N.C. (1993). A procedure for ranking efficient units in data envelopment analysis. Management Science, 39(10), 1261-1264.

Athanassopoulos, A.D., \& Shale, E. (1997). Assessing the comparative efficiency of higher education institutions in the uk by the means of data envelopment analysis. Education Economics, 5(2), 117-134.

Atici, K.B., \& Podinovski, V.V. (2015). Using data envelopment analysis for the assessment of technical efficiency of units with different specializations: An application to agriculture. Omega, 54, 72-83.

Avkiran, N.K. (2001). Investigating technical and scale efficiencies of Australian universities through data envelopment analysis. Socio-Economic Planning Sciences, 35(1), 57-80.

Banker, R.D. (1984). Estimating the most productive scale size using data envelopment analysis. European Journal of Operational Research, 17(1), 35-44.

Banker, R.D., Charnes, A., \& Cooper, W.W. (1984). Some models for estimating technical and scale inefficiencies in data envelopment analysis. Management Science, 30(9), 1078-1092.

Banker, R.D., Cooper, W.W., Seiford, L.M., Thrall, R.M., \& Zhu, J. (2004). Returns to scale in different DEA models. European Journal of Operational Research, 154(2), 345-362.

Banker, R.D., \& Morey, R.C. (1986). The use of categorical variables in data envelopment analysis. Management Science, 32(12), 1613-1627.

Beasley, J.E. (1990). Comparing university departments. Omega, 18(2), 171-183.

Beasley, J.E. (1995). Determining teaching and research efficiencies. Journal of the Operational Research Society, 46(4), 441-452.

Charnes, A., Cooper, W.W., Golany, B., Seiford, L., \& Stutz, J. (1985). Foundations of data envelopment analysis for Pareto-Koopmans efficient empirical production functions. Journal of Econometrics, 30(12), 91-107.

Charnes, A., Cooper, W.W., \& Rhodes, E. (1978). Measuring the efficiency of decision making units. European Journal of Operational Research, 2(6), 429-444.

Cook, W.D., Chai, D., Doyle, J.R., \& Green, R.H. (1998). Hierarchies and Groups in DEA. Journal of Productivity Analysis, 10(2), 177-198. 
Cooper, W.W., Seiford, L.M., \& Tone, K. (2007). Non-Discretionary and categorical variables. In Cooper, W.W., Seiford, L.M., Tone, K. (eds) Data Envelopment Analysis: A Comprehensive Text with Models, Applications, References and DEA-Solver Software. Springer, Boston, MA, 2nd ed., pp. 215-255.

Du, J., Zhu, J., Cook, W.D., \& Huo, J. (2015). DEA models for parallel systems: Game-Theoretic approaches. Asia-Pacific Journal of Operational Research, 32(2), 1550008.

Farrell, M.J. (1957). The measurement of productive efficiency. Journal of the Royal Statistical Society. Series A (General), 120(3), 253-293.

Førsund, F.R. (2002). Categorical variables in DEA. International Journal of Business and Economics, 1(1), 33-43.

Gholizadeh, H., \& Fazlollahtabar, H. (2019). Production control process using integrated robust data envelopment analysis and fuzzy neural network. International Journal of Mathematical, Engineering and Management Sciences, 4(3), 580-590.

Giménez, V.M., \& Martínez, J.L. (2006). Cost efficiency in the university: A departmental evaluation model. Economics of Education Review, 25(5), 543-553.

Jauhar, S.K., Pant, M., \& Dutt, R. (2018). Performance measurement of an Indian higher education institute: A sustainable educational supply chain management perspective. International Journal of System Assurance Engineering and Management, 9(1), 180-193.

Johnes, J. (2006a). Data envelopment analysis and its application to the measurement of efficiency in higher education. Economics of Education Review, 25(3), 273-288.

Johnes, J. (2006b). Measuring teaching efficiency in higher education: An application of data envelopment analysis to economics graduates from UK universities 1993. European Journal of Operational Research, 174(1), 443-456.

Johnes, J., \& Yu, Li. (2008). Measuring the research performance of Chinese higher education institutions using data envelopment analysis. China Economic Review, 19(4), 679-696.

Kao, C. (1998). Measuring the efficiency of forest districts with multiple working circles. Journal of the Operational Research Society, 49(6), 583-590.

Kao, C. (2000). Short-run and long-run efficiency measures for multiplant firms. Annals of Operations Research, 97(1-4), 379-388.

Kao, C. (2009). Efficiency measurement for parallel production systems. European Journal of Operational Research, 196(3), 1107-1112.

Kao, C., \& Hung, H.T. (2008). Efficiency analysis of university departments: An empirical study. Omega, 36(4), 653-664.

Kocher, M.G., Luptacik, M., \& Sutter, M. (2006). Measuring productivity of research in economics: A crosscountry study using DEA. Socio-Economic Planning Sciences, 40(4), 314-332.

Li, Y., Lei, X., Dai, Q., \& Liang, L. (2015). Performance evaluation of participating nations at the 2012 London summer olympics by a two-stage data envelopment analysis. European Journal of Operational Research, 243(3), 964-973.

McMillan, M.L., \& Datta, D. (1998). The relative efficiencies of canadian universities: a DEA perspective. Canadian Public Policy/Analyse de Politiques, 24(4), 485-511.

MHRD (2013). Rashtriya Uchchatar Shiksha Abhiyan: National Higher Education Mission. rusa.nic.in

MHRD (2015). All India Survey on Higher Education 2012-13. Department of Higher Education, Ministry of Human Resource Development, Government of India. 
Pastor, J.T., Ruiz, J.L., \& Sirvent, I. (1999). A statistical test for detecting influential observations in DEA. European Journal of Operational Research, 115(3), 542-554.

Planning Commission. (2013). Twelfth five year plan (2012-2017) social sectors: Vol. III (pp. 47-123). Sage Publications India Pvt Ltd.

http://mhrd.gov.in/sites/upload_files/mhrd/files/document-reports/XIIFYP_SocialSector.pdf

Ray, S.C., \& Jeon, Y. (2008). Reputation and efficiency: A non-parametric assessment of America's toprated MBA programs. European Journal of Operational Research, 189(1), 245-268.

Ruiz, J.L., Segura, J.V., \& Sirvent, I. (2015). Benchmarking and target setting with expert preferences: An application to the evaluation of educational performance of Spanish universities. European Journal of Operational Research, 242(2), 594-605.

Sagarra, M., Mar-Molinero, C., \& Agasisti, T. (2017). Exploring the efficiency of Mexican universities: Integrating data envelopment analysis and multidimensional scaling. Omega, 67, 123-133.

Sahoo, B.K., Singh, R., Mishra, B., \& Sankaran, K. (2017). Research productivity in management schools of India during 1968-2015: A directional benefit-of-doubt model analysis. Omega, 66, 118-139.

Saxena, P. (2019). A benchmarking strategy for Delhi transport corporation: An application of data envelopment analysis. International Journal of Mathematical, Engineering and Management Sciences, $4(1), 232-144$

Sexton, T.R., Silkman, R.H., \& Hogan, A.J. (1986). Data envelopment analysis: Critique and extensions. New Directions for Program Evaluation, 1986(32), 73-105.

Singh, S. (2011). Measuring the performance of teams in the Indian premier league. American Journal of Operations Research, 1(3), 180-184.

Singh, S., \& Ranjan, P. (2018). Efficiency analysis of non-homogeneous parallel sub-unit systems for the performance measurement of higher education. Annals of Operations Research, 269(1-2), 641-666.

Sinuany-Stern, Z., Mehrez, A., \& Barboy, A. (1994). Academic departments efficiency via DEA. Computers \& Operations Research, 21(5), 543-556.

Thanassoulis, E., Dey, P.K., Petridis, K., Goniadis, I., \& Georgiou, A.C. (2017). Evaluating higher education teaching performance using combined analytic hierarchy process and data envelopment analysis. Journal of the Operational Research Society, 68(4), 431-445.

Thanassoulis, E., Kortelainen, M., Johnes, G., \& Johnes, J. (2011). Costs and efficiency of higher education institutions in England: A DEA analysis. Journal of the Operational Research Society, 62(7), 12821297.

Tone, K. (2001). A slacks-based measure of efficiency in data envelopment analysis. European Journal of Operational Research, 130(3), 498-509.

Tyagi, P., Yadav, S.P., \& Singh, S.P. (2009). Relative performance of academic departments using DEA with sensitivity analysis. Evaluation and Program Planning, 32(2), 168-177. 